\title{
High use of complementary and alternative medication among children with autism is not associated with the severity of core symptoms
}

\author{
Joanna Granich ${ }^{1 *}$, Anna Hunt ${ }^{1 \dagger}$, David Ravine ${ }^{2 \dagger}$, John Wray ${ }^{3 \dagger}$ and Andrew J.O. Whitehouse ${ }^{1 \dagger}$ \\ *Correspondence: joanna.granich@telethonkids.org.au

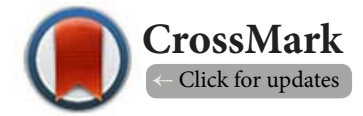 \\ 'These authors contributed equally to this work. \\ 'Telethon Kids Institute, The University of Western Australia, Australia. \\ ${ }^{2}$ School of Pathology and Laboratory Medicine, The University of Western Australia, Australia. \\ ${ }^{3}$ State Child Development Centre, Child and Adolescent Health Service, The University of Western Australia, Australia.
}

\begin{abstract}
Background: Complementary and alternative medicine (CAM) is commonly used by individuals with autism spectrum disorder (ASD). No study has examined individual, family and clinical characteristics associated with CAM use.

Methods: Parents of 169 Australian children with a clinical diagnosis of ASD completed a questionnaire about socio-demographics, medical history and CAM use. Children were administered the Autism Diagnostic Observation Schedule.

Results: The majority (54\%) of this sample had used CAM. Fish oil was the most common type of CAM administered ( $48 \%$ of total sample) and the most common reason for CAM use was to ameliorate noncore ASD symptoms such as hyperactivity and irritability. Chi-square analyses identified no differences between CAM and non-CAM users in gender, age of child, age at diagnosis, parental age at birth, parental education, ethnicity or family income. No group differences in the proportion of children classified with different ASD, based on clinical diagnosis and ADOS severity scores were observed. CAM users (37\%) were more likely than non-CAM users $(22 \%)$ to take psychotropic medication $(p<0.05)$.

Conclusions: This study provided evidence for high rate of CAM use in an Australian paediatric ASD population, similar to other countries. CAM use was not associated with core ASD deficits. There is a clear need for robust evidence to determine complex influencing factors on CAM uptake and its efficacy on ASD core and non-core symptoms with a view to assist with parental informed decisions and clinical guidelines.
\end{abstract}

Keywords: Autism spectrum disorder, adolescents, psychotropic medication, correlates, therapies

\section{Introduction}

Complementary and alternative medicine (CAM) refers to diagnostic, treatment and prevention philosophies and techniques that are based on traditional (often, non-Western) medicine that are used with (complementary) or in place of (alternative) conventional medicine. Over the past decade several surveys showed that general use of CAM is increasing in the developed world [1-4]. However, to date, there is no conceptual framework nor substantive evidence to account for the growth of CAM use as a stand-alone form of health care or when combined with conventional medicine [5]. Complex societal and psychosocial dimensions such as perceived control over health status, personal beliefs and values, philosophical orientations regarding health care and life, quests for lifestyle modification, expansion of health consumer choices, satisfaction or dissatisfaction with treatments, loyalty to different forms of medicine and practitioners, the nature and severity of certain conditions as well as socio-demographic factors have all been reported to shape CAM use [1,4-9]. Recently, the expansion of government and private funding of CAM practitioners, services and therapies in some countries have added another incentive for consumers to look towards CAM use. Overall, these factors collectively present a competing domain for conventional medicine and evidence-base clinical practice $[4,10]$. 
Granich et al. Journal of Autism 2014,

http://www.hoajonline.com/journals/pdf/2054-992X-1-4.pdf

doi: 10.7243/2054-992X-1-4

More specifically, the popularity of CAM use as a treatment option among the paediatric ASD population is also increasing [11-16]. International studies estimate the prevalence of CAM use in the paediatric ASD population to be between $35 \%$ and $95 \%[9,15,17]$, which compares with rates of between $10 \%$ and 30\% amongst children in the general population [18-21]. Studies have reported a variety of CAM used by children with ASD, with the most commonly reported being biologicallybased products such as dietary supplements, vitamins, minerals, natural and herbal remedies [22,23]. International estimates suggest that CAM use is widespread among individuals with ASD, but no empirical data currently exists on the prevalence among the Australian paediatric ASD community.

A recent review of CAM use in ASD found that many have unmet standards of clinical effectiveness, with a particular dearth of randomised clinical trials and replication studies [22]. Although CAM is well-tolerated in general, there is limited evidence for the efficacy of dietary and immune therapies, vitamin and fatty acid supplementation as a treatment for ASD [22,24-26]. Some novel CAM practices such as inhaling $100 \%$ oxygen in a pressurized chamber termed as hyperbaric oxygen therapy or the administration of intravenous secretin have shown no evidence at all for its efficacy [22]. Furthermore, controversial CAM in the form of chelation therapy is not only ineffective but also unsafe $[22,25]$.

There are a range of possible explanations for the incongruence between the paucity of scientific evidence for CAM and the high-prevalence of its use in the ASD population. For example, a general perception of CAM as a natural product lends itself to the notion of low risk [27]. Thus, CAM is perceived to be relatively safe with nil or fewer side effects when compared to psychotropic medication $[27,28]$. The heterogeneous nature of ASD and the presence of possible comorbidities highlight the complexity of ASD symptomology for which conventional treatments may not be effective [29] while for many families, interventions might be difficult to access or are prohibitive due to the inherent high costs [30]. In contrast, ease of access and availability of CAM which can be obtained online, from a local supermarket or a pharmacy without prescription is an appealing option. Similarly, the ease of use of CAM products as opposed to intense and sustained behavioural one-on-one or group therapy is another positive attribute of CAM and its adoption.

Currently, there are few studies of individuals with ASD that examine potential factors relating to CAM use in this population. A recent study found that children with ASD who had behavioural problems and food allergies were more likely to use CAM [15]. Parental experience of child-related stress was also associated with CAM use [15]. Intriguingly, stress among parents of children with ASD is known to be more common than among other parents of children [31] with severity of ASD as another influencing factor impacting on parental stress levels $[32,33]$. Thus, one possibility is that CAM use is more common among individuals with greater ASD symptom severity. To date, this has not been objectively examined in CAM and ASD related studies, but only examined through parental reports [34]. Other co-existing conditions such as gastrointestinal problems and seizure disorders have also been found to be associated with children's CAM use [35]. In other studies, Caucasian families [17], high socio-economic status [9] and high parental education [16] were factors that positively influenced CAM use as a treatment modality for ASD. Similarly, parental CAM use has been shown to influence child's consumption of CAM [12]. Time since ASD diagnosis is another reported factor to influence children's CAM consumption with those undergoing recent diagnosis more likely to use CAM [29]. Overall, the uptake of CAM for ASD symptoms appears to be influenced by multiple factors.

The first aim of this study was to survey a large sample of parents of children with ASD to determine the rate of CAM use within a large ASD sample. While studies in the US $[9,11,13,15,29,34,35]$, China [36], Canada [16,26] and Turkey [37] have found that CAM use is widespread among individuals with ASD, no empirical data currently exist on the rate of CAM use among the Australian paediatric ASD community. The second aim was to determine whether there was any relationship between CAM users; socio-demographics, the use of conventional medical treatment or type of clinical diagnosis of children with ASD. Finally, we hypothesise that children with ASD who use CAM are more likely to have severe core/autism symptoms.

\section{Methods}

\section{Participants}

The recruitment of participants was performed via advertising flyers and distributed among local service providers and clinicians. Therefore, this study's population comprised of volunteer participants who self-selected to become part of the Western Australian Autism Biological Registry (WAABR), which is an ongoing cross-sectional study of children and adolescents with ASD and their families taking place at the Telethon Kids Institute. The sample comprised of 169 children and adolescents, of which the majority were male $(n=133$, 79\%). Table 1 presents the characteristics of the population under investigation.

Ethics approval for WAABR was granted by the Human Ethics Committee at Princess Margaret Hospital for Children in Perth, Western Australia. WAABR participants are sourced through private, government and non-for-profit service providers, in addition to state-wide media and print advertising. Enrolment in the registry requires a clinical diagnosis of Autistic Disorder, Asperger's Disorder or Pervasive Developmental Disorder-Not Otherwise Specified (PDD-NOS). Diagnosis of these conditions in Western Australia mandates assessment by a clinical team comprising a Paediatrician, Clinical Psychologist and SpeechLanguage Pathologist under DSM-IV-TR guidelines and a diagnosis is only made when there is consensus amongst this multi-disciplinary team. The current study included all 
Table 1. Characteristics of children with ASD $(n=169)$ and their parents.

\begin{tabular}{|c|c|}
\hline Characteristics & n (\%) \\
\hline \multicolumn{2}{|l|}{ Child's gender } \\
\hline Male & $133(78.7)$ \\
\hline Female & $36(21.3)$ \\
\hline \multicolumn{2}{|l|}{ Child's age } \\
\hline$<5$ & $42(24.9)$ \\
\hline $5-10$ & $69(40.8)$ \\
\hline$>10$ & $58(34.3)$ \\
\hline \multicolumn{2}{|l|}{ Child's age at clinical diagnosis } \\
\hline$<5$ & $109(67.7)$ \\
\hline $5-10$ & $37(23.0)$ \\
\hline$>10$ & $15(9.3)$ \\
\hline \multicolumn{2}{|l|}{ Maternal age at child's birth } \\
\hline$<25$ & $21(12.4)$ \\
\hline $25-35$ & $108(63.9)$ \\
\hline$>35$ & $39(23.1)$ \\
\hline \multicolumn{2}{|l|}{ Maternal ethnicity } \\
\hline Caucasian & $153(91.1)$ \\
\hline Non-Caucasian ${ }^{\wedge}$ & $15(8.9)$ \\
\hline \multicolumn{2}{|l|}{ Highest maternal education } \\
\hline Did not complete secondary school & $26(15.4)$ \\
\hline Secondary school completion & $40(23.7)$ \\
\hline Trade/Technical certificate & $38(22.5)$ \\
\hline Bachelor degree or higher & $65(38.5)$ \\
\hline \multicolumn{2}{|l|}{ Paternal age at child's birth } \\
\hline$<25$ & $15(8.9)$ \\
\hline $25-35$ & $95(56.2)$ \\
\hline$>35$ & $57(33.7)$ \\
\hline \multicolumn{2}{|l|}{ Paternal ethnicity } \\
\hline Caucasian & $150(89.3)$ \\
\hline Non-Caucasian ${ }^{\wedge}$ & $18(10.7)$ \\
\hline \multicolumn{2}{|l|}{ Highest paternal education } \\
\hline Did not complete secondary school & $29(17.2)$ \\
\hline Secondary school completion & $26(15.4)$ \\
\hline Trade/Technical certificate & $52(30.8)$ \\
\hline Bachelor degree or higher & $57(33.7)$ \\
\hline \multicolumn{2}{|l|}{ Family income } \\
\hline$<\$ 30,000$ & $8(4.7)$ \\
\hline$\$ 30,001-\$ 60,000$ & $24(14.2)$ \\
\hline$\$ 60,001-\$ 104,000$ & $48(28.4)$ \\
\hline$>\$ 104,001$ & $85(50.3)$ \\
\hline
\end{tabular}

${ }^{\wedge}$ Non-Caucasian represents Indigenous Aboriginal, Asian, Maori or Pacific Islander, Latino and Arab. participants who voluntarily enrolled in the registry as of November 2012, and who completed information on CAM use $(n=169)$.

\section{Procedure}

Participants were invited to Telethon Kids Institute where informed consent was sought from primary caregivers. To confirm the clinical diagnosis, all children were administered the Autism Spectrum Disorder Observation ScheduleGeneric (ADOS-G) [38] by the same research-accredited professional. The ADOS-G is a semi-structured assessment that uses simple activities and questions to elicit and observe the communicative and social behaviours relevant to the diagnosis of ASD. Each participant's total of ADOS-G raw scores were mapped onto a calibrated severity score (and ADOS classification) derived from an algorithm module and the participant's chronological age within the respective module [39].

Prior to the testing session, parents were mailed a package containing a case-history questionnaire, which sought data on family socio-demographics, early child development, pregnancy and birth history, and health of biological parents. A section of the case-history questionnaire related to the use of CAM, included the following question:"Some parents seek natural therapies for their child. Please provide details of any natural therapies your child has taken". Parents were asked to list the name of the therapy used, the child's age when this was first used and the reason for using this therapy. A subsequent question asked whether the child had taken any prescription medication. Again, parents were asked to provide the name of the medication, the child's age when this was first used and the reason for using the medication. This study adapted a classification system for CAM therapies [40].

\section{Analysis}

The data were analysed using Statistical Package for Social Sciences (SPSS Version 19 for Windows). Descriptive statistics are presented as mean (SDI) or percentage to describe the sample. Children were dichotomized to either the CAM user or non-CAM user group based on whether or not their caregiver reported that the child had ever used CAM. Differences between groups (CAM user vs non-CAM user) were assessed via chi-square test $\left(X^{2}\right)$. The level of significance was $P$ value $\leq 0.05$ (two-tailed) throughout this investigation.

\section{Results}

Table 1 presents the characteristics of the sample under investigation. The average age of children when clinical diagnosis was obtained was 5.07 years $(S D=3.62)$. The average age of children when they were assessed for the current study was 8.57 years $(S D=4.8)$.

Parent report indicated that over half $(n=92,54.4 \%)$ of children in this sample had been administered CAM. Table 2 shows that the most common type of CAM was extracts from 
Granich et al. Journal of Autism 2014,

http://www.hoajonline.com/journals/pdf/2054-992X-1-4.pdf

Table 2. Types of complementary and alternative medications (CAM) used by children with ASD $(n=169)$.

\begin{tabular}{ll}
\hline CAM & $\mathbf{n}(\%)$ \\
\hline Category & \\
\hline Natural health practices: homeopathy & $8(4.7)$ \\
Herbal therapies & $9(5.3)$ \\
Dietary therapies & $14(8.3)$ \\
Vitamins & $35(20.7)$ \\
Minerals & $19(11.2)$ \\
Extracts from organisms: fish oil & $81(47.9)$ \\
Physical therapies: massage & $4(2.4)$ \\
\hline Number of different categories used & \\
\hline 0 & $77(45.6)$ \\
1 & $40(23.7)$ \\
2 & $30(17.8)$ \\
3 & $18(10.7)$ \\
4 & $4(2.4)$ \\
\hline
\end{tabular}

organisms such as fish oil ( $\mathrm{n}=81,47.9 \%)$, followed by vitamins $(n=35,20.7 \%)$ and then minerals $(n=19,11.2 \%)$. Among the children that had been administered CAM, one third $(n=52$, $30.9 \%$ ) had used two or more different types of CAM. Parents reported the most common reason for CAM use was to improve non-core ASD symptoms (Table 3). These included hyperactivity, inattention, irritability and aggression. The next most common reason for CAM use was for children's general health and well-being with poor diet as the most frequently cited motive for its use. The third most common reason for CAM use was to improve their child's gastro-intestinal problems, of which constipation and loose stools were frequently reported.

Using chi-square analyses, we examined socio-demographic factors that may differentiate the two groups (Table 4). Psychotropic medication use was more common among CAM users $(n=34,37 \%)$ compared to non-CAM users ( $n=17,22 \%)$, $\left(x^{2}=4.404 d f=1, p=0.036\right)$. No further significant differences were observed.

Table 5 shows that the vast majority $(n=143,84.6 \%)$ of children had a clinical diagnosis of Autistic Disorder, while a small number of children had a clinical diagnosis of PDDNOS ( $n=13,15 \%)$ or Asperger's Disorder ( $n=13,15 \%)$. The proportion of children with each diagnosis was the same among CAM and non-CAM users. At research assessment, 99 (58.5\%) children met criteria for Autism on the ADOS-G and $17(10.0 \%)$ met criteria for Autism Spectrum Disorder, while $39(23.0 \%)$ children did not meet criteria for either diagnosis. Overall, the proportion of children classified with each diagnosis according to the ADOS severity scales did not differ as a function of CAM-use.

\section{Discussion and conclusion}

This study confirmed the popularity of CAM use among a large
Table 3. Reasons for the use of complementary and alternative medications (CAM) for children with ASD as reported by parents $(\mathbf{n}=92)$.

\begin{tabular}{ll}
\hline Reasons $^{\mathbf{a}}$ & $\mathbf{n}(\%)^{\mathbf{b}}$ \\
\hline Core ASD symptoms $^{*}$ & $11(11.3)$ \\
Non-Core ASD symptoms $^{\dagger}$ & $57(61.3)$ \\
Co-morbidities $^{\ddagger}$ & $7(7.5)$ \\
\hline Non-ASD specific symptoms $^{\dagger}$ & \\
\hline Immune problems and allergies & $13(14.0)$ \\
Gastro-intestinal track problems & $20(21.5)$ \\
General health and well-being & $22(23.7)$ \\
Detox & $4(4.3)$ \\
Sleep problems & $10(10.8)$ \\
Other & $14(15.1)$ \\
\hline
\end{tabular}

${ }^{\mathrm{a}} 158$ reported reasons.

bercent of cases.

*social communication, language deficits, restricted and repetitive behaviours.

thyperactivity, inattention, irritability, aggression.

*dyspraxia, attention deficit disorder, attention deficit hyperactivity disorder, anemia.

^migraines, common cold, cracked lips.

sample of Australian children with ASD. The proportion of children in the current study who used CAM was $54 \%$, which compares with $50-70 \%$ in Canada [26], 32\%-92\% in the USA [13], and $40.8 \%$ in China [36]. This study also found the most common type of CAM consumed was fish oil (47.9\%) followed by vitamins (20.7\%) and minerals (11.2\%). Previous studies in this area have seldom collected detailed data on the specific types of CAM consumed by children. Among the few reports that did, $1-29 \%$ of children with ASD used essential fatty acids $[16,34]$, while $22-43 \%$ consumed vitamins $[16,17]$.

The most common reason parents cited for their children using CAM was to ameliorate non-core symptoms of ASD. This study also found that one third of children who consumed CAM were using at least two different types. This rate is slightly lower than other studies where approximately half of the sub-sample used more than one CAM $[13,15]$. However, these comparisons need to be viewed in light of the current and previous CAM related studies using different measures of CAM among geographically different ASD paediatric populations. Nevertheless, this study and the aforementioned comparisons provide useful insight in to the widespread use of CAM among clinically diagnosed children with ASD in the world and specifically in Australia.

The current study observed no relationship between the majority of child or socio-demographic factors and the propensity for CAM use among children with ASD. This finding stands in contrast to other investigations which found that being Caucasian [17], having parents with high level of education [16] and of high socio-economic status 
Granich et al. Journal of Autism 2014,

http://www.hoajonline.com/journals/pdf/2054-992X-1-4.pdf

doi: 10.7243/2054-992X-1-4

Table 4. Factors associated with CAM use among children with $\operatorname{ASD}(n=169)$.

\begin{tabular}{|c|c|c|c|}
\hline Factors & $\begin{array}{l}\text { CAM user } \\
\text { n (\%) }\end{array}$ & $\begin{array}{l}\text { non-CAM user } \\
\text { n (\%) }\end{array}$ & $p$-value \\
\hline \multicolumn{4}{|l|}{ Child's gender } \\
\hline Male & $69(75.0)$ & $64(83.1)$ & \multirow{2}{*}{0.19} \\
\hline Female & $23(25.0)$ & $13(16.9)$ & \\
\hline \multicolumn{4}{|l|}{ Child's age } \\
\hline$<5$ & $21(22.8)$ & $21(27.3)$ & \multirow{3}{*}{0.78} \\
\hline $5-10$ & $38(41.3)$ & $31(40.3)$ & \\
\hline$>10$ & $33(35.9)$ & $25(32.5)$ & \\
\hline \multicolumn{4}{|l|}{ Child's age at clinical diagnosis } \\
\hline$<5$ & $61(56.0)$ & $48(44.0)$ & \multirow{3}{*}{0.76} \\
\hline $5-10$ & $23(62.2)$ & $14(37.8)$ & \\
\hline$>10$ & $8(53.3)$ & $7(46.7)$ & \\
\hline \multicolumn{4}{|l|}{ Psychotropic medication } \\
\hline User & $34(37.0)$ & $17(22.1)$ & \multirow{2}{*}{$0.03^{*}$} \\
\hline Non-user & $58(63.0)$ & $60(77.9)$ & \\
\hline \multicolumn{4}{|l|}{ Maternal age at child's birth } \\
\hline$<25$ & $9(9.9)$ & $12(15.6)$ & \multirow{3}{*}{0.48} \\
\hline $25-35$ & $59(64.8)$ & $49(63.6)$ & \\
\hline$>35$ & $23(25.3)$ & $16(20.8)$ & \\
\hline \multicolumn{4}{|l|}{ Maternal ethnicity } \\
\hline Caucasian & $85(92.4)$ & $68(89.5)$ & \multirow{2}{*}{0.50} \\
\hline Non-Caucasian^ & $7(7.6)$ & $8(10.5)$ & \\
\hline \multicolumn{4}{|l|}{ Highest maternal education } \\
\hline $\begin{array}{l}\text { Did not complete secondary } \\
\text { school }\end{array}$ & $10(10.9)$ & $16(20.8)$ & \multirow{4}{*}{0.34} \\
\hline Secondary school completion & $24(26.1)$ & $16(20.8)$ & \\
\hline Trade/Technical certificate & $21(22.8)$ & $17(22.1)$ & \\
\hline Bachelor degree or higher & $37(40.2)$ & $28(36.4)$ & \\
\hline \multicolumn{4}{|l|}{ Paternal age at child's birth } \\
\hline$<25$ & $6(6.6)$ & $9(11.8)$ & \multirow{3}{*}{0.28} \\
\hline $25-35$ & $50(54.9)$ & $45(59.2)$ & \\
\hline$>35$ & $35(38.5)$ & $22(28.9)$ & \\
\hline \multicolumn{4}{|l|}{ Paternal ethnicity } \\
\hline Caucasian & $84(91.3)$ & $66(86.8)$ & \multirow{2}{*}{0.35} \\
\hline Non-Caucasian^ & $8(8.7)$ & $10(13.2)$ & \\
\hline \multicolumn{4}{|l|}{ Highest paternal education } \\
\hline $\begin{array}{l}\text { Did not complete secondary } \\
\text { school }\end{array}$ & $18(19.8)$ & $11(15.1)$ & \multirow{4}{*}{0.66} \\
\hline Secondary school completion & $15(16.5)$ & $11(15.1)$ & \\
\hline Trade/Technical Certificate & $30(33.0)$ & $22(30.1)$ & \\
\hline Bachelor degree or higher & $28(30.8)$ & $29(39.7)$ & \\
\hline \multicolumn{4}{|l|}{ Family income } \\
\hline$<\$ 60,000$ & $20(22.2)$ & $12(16.0)$ & \multirow{3}{*}{0.58} \\
\hline$\$ 60,001-\$ 104,000$ & $26(28.9)$ & $22(29.3)$ & \\
\hline$>\$ 104,001$ & $44(48.9)$ & $41(54.7)$ & \\
\hline
\end{tabular}

${ }^{\wedge}$ Non-Caucasian represents Indigenous Aboriginal, Asian, Maori or Pacific Islander, Latino and Arab.

${ }^{*} \mathrm{P} \leq 0.05$ for differences between CAM users and non-CAM users.
Table 5. Autism diagnoses and type of CAM user $(n=169)$.

\begin{tabular}{llll}
\hline Diagnoses & $\begin{array}{l}\text { CAM user } \\
\mathbf{n}(\%)\end{array}$ & $\begin{array}{l}\text { non-CAM user } \\
\mathbf{n}(\%)\end{array}$ & $p$-value \\
\hline $\begin{array}{l}\text { Autism spectrum (Clinical) } \\
\text { diagnosis }^{\wedge}\end{array}$ & & & \\
\hline Autistic disorder & $75(81.5)$ & $68(88.3)$ & \\
PDD-NOS & $9(9.8)$ & $4(5.2)$ & 0.44 \\
Asperger disorder & $8(8.7)$ & $5(6.5)$ & \\
\hline $\begin{array}{l}\text { ADOS classifications at } \\
\text { research assessment }\end{array}$ & & & \\
\hline Non-spectrum & $19(22.6)$ & $20(28.2)$ & \\
Autism spectrum disorder & $9(10.7)$ & $8(11.3)$ & 0.70 \\
Autism & $56(66.7)$ & $43(60.6)$ & \\
\hline
\end{tabular}

${ }^{\wedge}$ Parent reported.

${ }^{\dagger} \mathrm{ADOS}$ totals raw scores were mapped onto calibrated severity scores (corresponding to ADOS classifications) derived from algorithm modules and chronological age within respective ADOS module [39].

[15] positively influenced CAM use in children with ASD. One possibility for the null findings of the current study is that, while the sample was large, it may not have possessed adequate heterogeneity in education, ethnicity and socio-economic status of parents to identify differences. One factor that did distinguish the two CAM user groups in this study was the use of psychotropic medication, in which CAM use was more common among children with ASD who were also taking psychotropic medication. To the best of our knowledge this is the first study to report such finding.

There are several possibilities for why children taking psychotropic medication are more likely to use CAM. The first relates to parental factors. Parents who seek out and obtain psychotropic medication for their children may also be more willing to administer CAM. While the current study was unable to directly test this possibility, there is evidence from a review of interventions used by families of school-age children that majority of parents use a combination of medication, dietary and CAM treatments for autism [14]. Furthermore, a study of individuals with psychiatric comorbidities and ASD reported the use of both psychotropic and non-psychotropic medications over time [41].

A second possibility relates to our third hypothesis: children with ASD who use CAM have more severe ASD symptomatology. More severe core ASD symptoms characterised by a triad of impairments in language, social communication and restricted repetitive behaviours may present as more troublesome behaviours. These behaviours often pose challenges for the child and for parents having to compromise and manage troublesome behaviours in a variety of settings. In addition, core ASD symptoms are atypical characteristics that impede children's daily functioning, reduce their capacity to learn and negatively impact on social interactions. Caregivers may be more likely to use CAM (and psychotropic medication) if their 
Granich et al. Journal of Autism 2014,

child has more challenging behaviours. However, our results do not support this hypothesis, finding no link between CAM use and a range of indices of ASD symptomatology. This finding is inconsistent with previous research that showed that CAM use is positively correlated with the severity of autism symptoms and subsequent diagnosis [13,17,42]. A plausible explanation for this inconsistency may be in the way the data on severity of autism symptoms was collected. Children who participated in this study were required to meet research criteria which stipulated a clinical diagnosis of ASD. Therefore, this study directly used the ADOS to validate participants' original diagnosis in addition to using the formula of Gotham et al. ,(2009) to generate an autism severity score from the ADOS test scores for each child. In comparison, previous research relied on parental report to obtain information on the original diagnosis of autism $[13,17,42]$, thus it is subject to recall bias. Therefore, the current study's data collection methods on the diagnosis and severity of autism might be viewed as more accurate given that the ADOS, an assessment that has high specificity and sensitivity for diagnosing ASD [43], was administered upon entry into this study. Around one-quarter of the children in the current study, all of whom had a clinical diagnosis of ASD, did not reach ASD criteria according to the ADOS. In each case, a consensus diagnosis had been made by a pediatrician, psychologist and speech pathologist, and thus we believe it unlikely that the mismatch between clinical and research classification is due to original misdiagnosis. A recent report indicated that $19.2 \%$ of children originally diagnosed with ASD do not meet full criteria for ASD when assessed at a later time-point [43]. Therefore, it is possible that a similar phenomenon has occurred in the current sample.

A third possibility for why children taking psychotropic medication are more likely to take CAM relates to the non-core symptoms of ASD. In the current study, parents reported that they often administered CAM to their children to ameliorate externalising behaviours such as hyperactivity, inattention, irritability and aggression. This finding replicates the results of a recent study that identified hyperactivity and irritability to be associated with children's CAM use [15]. Externalizing behaviours in ASD are often treated with psychotropic medication [44], specifically methylphenidate (Ritalin) [45-47] and Dexamphetamine (Dexedrine) $[\mathbf{4 8 , 4 9 ]}$. It is possible that the link between psychotropic medication and CAM use observed in the current study is a reflection of parents seeking multiple medications to treat the same behaviours in a bid to find an effective treatment for their child with ASD-a life-long condition. The nature of autism may predispose parents to try different or a combination of treatment modalities. More broadly, it is possible that this is an emerging societal and healthcare shift in the treatment paradigm where conventional and pharmacological modalities are integrated with CAM practices. This paradigm shift has been identified as Integrative (Mental) Health Care [50,51]. It seeks to address not only the acute symptoms of a condition but also cultural, spiritual, economic and environmental determinants of living with a condition in a bid to improve overall health and well-being with an attempt to lead a better and fulfilled life [51].

In summary, the current study confirmed that CAM use is common among children with ASD in Australia. We found that CAM is more common among children also taking psychotropic medication, and that CAM use was unrelated to the severity of ASD. The strengths of this study were the large paediatric sample size that was recruited from a single geographical area. We also directly assessed symptomatology using the ADOS, which stands in contrast to prior research in this area where often information on clinical diagnoses is obtained from parental recalls $[13,34,42]$ or medical records [17]-methodologies that are subject to recall and inter-rater biases.

However, a limitation of the current study was that the participants represented a convenience sample and may not be representative of the broader ASD population. While this sampling methodology may have an incorporated systematic bias that influenced the findings, it is important to note that there was a good representation of participants across socioeconomic strata (Table 1) and severity of ASD (Table 5) but not for ethnicity (Table 1).

Given the high-rate of CAM use, more robust research is needed to provide comprehensive insights into usage patterns; motivations of families for the uptake CAM as a treatment modality for ASD, and a myriad of influencing factors along life course of children with ASD. The highly accessible world wide web opens up a myriad of information about ASD treatment possibilities for many vulnerable parents who are desperately seeking an effective treatment for their child with ASD [13]. However, this poses an inevitable risk for misinformation and an overwhelming amount of case studies that usually provide miracle testimonials and report benefit outcomes of various CAM therapies for children with ASD with limited consideration for the biological rationale, scientific rigor or safety of these treatments [52]. This is coupled with some CAM users having a misconceived notion that CAM is a safer option when compared with conventional medication because CAM is thought to be naturally derived [53]. Although an enhanced therapeutic effect is desirable for any drug or therapy, in some cases certain combinations of medications are likely to have an adverse effect [54] and are contraindicated as in drug-herb interaction such as those found between St John's Wort and psychotropic medication [55]. This underscores the importance of adequate knowledge in evaluating the risk-to-benefit ratio of CAM and conventional medication use.

Although not without challenge, strengthening the evidence base for CAM and ASD in children through placebo-controlled clinical trials are warranted, to provide more quality evidence to determine CAM level of efficacy and safety. Continuing education for clinicians' about CAM and enhancing their knowledge and skill set to evaluate CAM evidence, risk-tobenefit and ultimately advise on safety and contraindications 
Granich et al. Journal of Autism 2014,

http://www.hoajonline.com/journals/pdf/2054-992X-1-4.pdf

for patients with ASD is essential for an effective health care practice. Developing clinical guidelines whether they are based on systematic reviews or expert opinion and clinical experience is nevertheless significant and critical especially when the latter is the best form of evidence that is currently available [56] such as for CAM and ASD. These are important steps that both CAM professional bodies and medical organisations in the United Kingdom [57] and in Australia [10,58] are starting to embrace. However, the success of such clinical statements or guidelines only lies in the way the information is promoted and shared among all types of practitioners; how competently it is applied and how well it is communicated to patients and consumers. Evidence-based knowledge about CAM and how to best integrate CAM with conventional medicine when treating children with ASD is integral to ethical and best practice medical repertoire. Similarly, evidence-based information needs to be provided to families in a timely manner so that it equips parents with adequate knowledge about CAM therapies which may influence families to make better and more informed decisions about CAM options in managing their child's disability.

\section{Competing interests}

The authors declare that they have no competing interests.

Authors' contributions

\begin{tabular}{|l|c|c|c|c|c|}
\hline Authors' contributions & JG & AH & DR & JW & AJOW \\
\hline Research concept and design & -- & -- & $\checkmark$ & $\checkmark$ & $\checkmark$ \\
\hline Collection and/or assembly of data & -- & $\checkmark$ & -- & -- & -- \\
\hline Data analysis and interpretation & $\checkmark$ & -- & -- & -- & $\checkmark$ \\
\hline Writing the article & $\checkmark$ & -- & -- & -- & -- \\
\hline Critical revision of the article & $\checkmark$ & -- & -- & $\checkmark$ & $\checkmark$ \\
\hline Final approval of article & $\checkmark$ & $\checkmark$ & $\checkmark$ & $\checkmark$ & $\checkmark$ \\
\hline Statistical analysis & $\checkmark$ & -- & -- & -- & $\checkmark$ \\
\hline
\end{tabular}

\section{Acknowledgement}

The authors wish to thank WAABR families for their willingness, time and effort to participate in the study. AJOW is supported by a Career Development Fellowship (\#1004065) from the National Health and Medical Research Council.

\section{Publication history}

Editors: Michael B Blank, University of Pennsylvania, USA.

Larry Jarrett Barnhill, University of North Carolina at Chapel Hill, USA.

Received: 30-Jul-2014 Final Revised: 16-Sep-2014

Accepted: 01-Oct-2014 Published: 06-Oct-2014

\section{References}

1. Van Haselen RA, Reiber U, Nickel I, Jakob A and Fisher PA. Providing Complementary and Alternative Medicine in primary care: the primary care workers' perspective. Complement Ther Med. 2004; 12:6-16. | Article | PubMed

2. Barnes P.M et al. Complementary and alternative medicine use among adults and children: United States, 2007. US Department of Health and Human Services, Centers for Disease Control and Prevention. National Center for Health Statistics Hyattsville. 2008 | Pdf

3. Xue CC, Zhang AL, Lin V, Da Costa C and Story DF. Complementary and alternative medicine use in Australia: a national population-based survey. J Altern Complement Med. 2007; 13:643-50. I Article I PubMed

4. Perry R, Dowrick $C$ and Ernst E. Complementary medicine and general practice in an urban setting: a decade on. Prim Health Care Res Dev. 2014; 15:262-7. | Article | PubMed

5. Bodeker $\mathrm{G}$ et al. WHO global atlas of traditional, complementary and alternative medicine. text volume: World Health Organization, Centre for Health Development. 2005. I Website

6. Astin JA. Why patients use alternative medicine: results of a national study. JAMA. 1998; 279:1548-53. | Article | PubMed

7. Ernst $E$. Prevalence of use of complementary/alternative medicine: a systematic review. Bull World Health Organ. 2000; 78:252-7. I PubMed Abstract | PubMed Full Text

8. Coulter ID and Willis EM. The rise and rise of complementary and alternative medicine: a sociological perspective. Med J Aust. 2004; 180:587-9. | Article | PubMed

9. Harrington JW, Rosen L, Garnecho A and Patrick PA. Parental perceptions and use of complementary and alternative medicine practices for children with autistic spectrum disorders in private practice. J Dev Behav Pediatr. 2006; 27:S156-61. | Article I PubMed

10. Government A. The Review of the Australian Government Rebate on Private Health Insurance for Natural Therapies. I Website

11. Levy SE and Hyman SL. Use of complementary and alternative treatments for children with autistic spectrum disorders is increasing. Pediatr Ann. 2003; 32:685-91. | Article | PubMed

12. Levy SE and Hyman SL. Complementary and alternative medicine treatments for children with autism spectrum disorders. Child Adolesc Psychiatr Clin N Am. 2008; 17:803-20. | Article | PubMed Abstract | PubMed Full Text

13. Christon L M, V.H. Mackintosh and B J Myers. Use of complementary and alternative medicine (CAM) treatments by parents of children with autism spectrum disorders. Research in Autism Spectrum Disorders. 2010; 4:249-259. | Article

14. Carter $M$ et al. Interventions used with an Australian sample of preschool children with autism spectrum disorders. Research in Autism Spectrum Disorders. 2011; 5:1033-1041. | Article

15. Valicenti-McDermott M, Burrows B, Bernstein L, Hottinger K, Lawson K, Seijo R, Schechtman M, Shulman L and Shinnar S. Use of complementary and alternative medicine in children with autism and other developmental disabilities: associations with ethnicity, child comorbid symptoms, and parental stress. J Child Neurol. 2014; 29:360-7. | Article I PubMed

16. Wong $\mathrm{HH}$ and Smith RG. Patterns of complementary and alternative medical therapy use in children diagnosed with autism spectrum disorders. J Autism Dev Disord. 2006; 36:901-9. | Article I PubMed

17. Hanson E, Kalish LA, Bunce E, Curtis C, McDaniel S, Ware J and Petry $J$. Use of complementary and alternative medicine among children diagnosed with autism spectrum disorder. J Autism Dev Disord. 2007; 37:628-36. I Article I PubMed

18. Davis MP and Darden PM. Use of complementary and alternative medicine by children in the United States. Arch Pediatr Adolesc Med. 2003; 157:393-6. | Article | PubMed

19. MacLennan AH, Myers SP and Taylor AW. The continuing use of complementary and alternative medicine in South Australia: costs and beliefs in 2004. Med J Aust. 2006; 184:27-31. | Article | PubMed

20. Crawford NW, Cincotta DR, Lim A and Powell CV. A cross-sectional survey of complementary and alternative medicine use by children and adolescents attending the University Hospital of Wales. BMC Complement Altern Med. 2006; 6:16. | Article | PubMed Abstract | PubMed Full Text

21. Birdee GS, Phillips RS, Davis RB and Gardiner P. Factors associated with pediatric use of complementary and alternative medicine. Pediatrics. 2010; 125:249-56. | Article | PubMed Abstract | PubMed Full Text

22. Whitehouse AJ. Complementary and alternative medicine for autism spectrum disorders: rationale, safety and efficacy. J Paediatr Child Health. 2013; 49:E438-42:quiz E442. I Article I PubMed

23. Semple $S$ et al. Complementary Medicine Products Used in AutismEvidence for Efficacy and Safety, in Autism Spectrum Disorders-From Genes to Environment, T. Williams, Editor. In Tech. 2011; 400. | Pdf 
Granich et al. Journal of Autism 2014,

24. Akins RS, Angkustsiri K and Hansen RL. Complementary and alternative medicine in autism: an evidence-based approach to negotiating safe and efficacious interventions with families. Neurotherapeutics. 2010; 7:307-19. | Article | PubMed

25. Lofthouse N, Hendren R, Hurt E, Arnold LE and Butter E. A review of complementary and alternative treatments for autism spectrum disorders. Autism Res Treat. 2012; 2012:870391. | Article | PubMed Abstract | PubMed Full Text

26. Anagnostou $E$ and Hansen R. Medical treatment overview: traditional and novel psycho-pharmacological and complementary and alternative medications. Curr Opin Pediatr. 2011; 23:621-7. | Article | PubMed

27. Weekes L. Making informed choices about complementary medicines. Health Voices. Journal of the Consumers Health Forum of Australia. 2012; 4-5. | Pdf

28. Huffman LC, Sutcliffe TL, Tanner IS and Feldman HM. Management of symptoms in children with autism spectrum disorders: a comprehensive review of pharmacologic and complementary-alternative medicine treatments. J Dev Behav Pediatr. 2011; 32:56-68. | Article | PubMed

29. Levy SE, Mandell DS, Merhar S, Ittenbach RF and Pinto-Martin JA. Use of complementary and alternative medicine among children recently diagnosed with autistic spectrum disorder. J Dev Behav Pediatr. 2003; 24:418-23. | Article | PubMed

30. Wilson M. Falling Short: Parents' Struggle To Afford Autism In Australia And The United States. 2011. | Pdf

31. Baker-Ericzn M J, L Brookman-Frazee and A Stahmer. Stress levels and adaptability in parents of toddlers with and without autism spectrum disorders. Research and Practice for Persons with Severe Disabilities. 2005; 30:194-204. I Pdf

32. Tomanik S, G E Harris and J. Hawkins. The relationship between behaviours exhibited by children with autism and maternal stress. Journal of Intellectual and Developmental Disability. 2004; 29:16-26. | Article

33. Allen K A, T V Bowles and L L Weber. Mothers' and fathers' stress associated with parenting a child with autism spectrum disorder. Autism Insights. 2013; 5:1-11. I Article

34. Green VA, Pituch KA, Itchon J, Choi A, O'Reilly M and Sigafoos J. Internet survey of treatments used by parents of children with autism. Res Dev Disabil. 2006; 27:70-84. | Article | PubMed

35. Perrin JM, Coury DL, Hyman SL, Cole L, Reynolds AM and Clemons T. Complementary and alternative medicine use in a large pediatric autism sample. Pediatrics. 2012; 130 Suppl 2:S77-82. | Article | PubMed

36. Wong VC. Use of complementary and alternative medicine (CAM) in autism spectrum disorder (ASD): comparison of Chinese and western culture (Part A). J Autism Dev Disord. 2009; 39:454-63. | Article | PubMed

37. Senel HG. Parents' views and experiences about complementary and alternative medicine treatments for their children with autistic spectrum disorder. J Autism Dev Disord. 2010; 40:494-503. | Article | PubMed

38. Lord C, Risi S, Lambrecht L, Cook EH, Jr., Leventhal BL, DiLavore PC Pickles $A$ and Rutter $M$. The autism diagnostic observation schedulegeneric: a standard measure of social and communication deficits associated with the spectrum of autism. J Autism Dev Disord. 2000; 30:205-23. | PubMed

39. Gotham K, Pickles A and Lord C. Standardizing ADOS scores for a measure of severity in autism spectrum disorders. J Autism Dev Disord. 2009; 39:693-705. | Article | PubMed Abstract | PubMed Full Text

40. Yap KP, McCready DR, Fyles A, Manchul L, Trudeau M and Narod S. Use of alternative therapy in postmenopausal breast cancer patients treated with tamoxifen after surgery. Breast J. 2004; 10:481-6. | Article I PubMed

41. Esbensen AJ, Greenberg JS, Seltzer MM and Aman MG. A longitudinal investigation of psychotropic and non-psychotropic medication use among adolescents and adults with autism spectrum disorders. J Autism Dev Disord. 2009; 39:1339-49. | Article | PubMed Abstract | PubMed Full Text

42. Goin-Kochel R P, V H Mackintosh and B J Myers. Parental reports on the efficacy of treatments and therapies for their children with autism spectrum disorders. Research in Autism Spectrum Disorders. 2009;
3:528-537. | Article

43. Falkmer T, Anderson K, Falkmer M and Horlin C. Diagnostic procedures in autism spectrum disorders: a systematic literature review. Eur Child Adolesc Psychiatry. 2013; 22:329-40. | Article | PubMed

44. Riesgo R, C Gottfried and M Becker. Clinical Approach in Autism: Management and Treatment. 2013. | Website

45. Simonoff E, Pickles A, Charman T, Chandler S, Loucas T and Baird G. Psychiatric disorders in children with autism spectrum disorders: prevalence, comorbidity, and associated factors in a population-derived sample. J Am Acad Child Adolesc Psychiatry. 2008; 47:921-9. | Article | PubMed

46. Shea S, Turgay A, Carroll A, Schulz M, Orlik H, Smith I and Dunbar F. Risperidone in the treatment of disruptive behavioral symptoms in children with autistic and other pervasive developmental disorders. Pediatrics. 2004; 114:e634-41. | Article | PubMed

47. McDougle CJ, Scahill L, Aman MG, McCracken JT, Tierney E, Davies M, Arnold LE, Posey DJ, Martin A, Ghuman JK, Shah B, Chuang SZ, Swiezy NB, Gonzalez NM, Hollway J, Koenig K, McGough JJ, Ritz L and Vitiello $B$. Risperidone for the core symptom domains of autism: results from the study by the autism network of the research units on pediatric psychopharmacology. Am J Psychiatry. 2005; 162:1142-8. | Article | PubMed

48. Arnold LE, Aman MG, Cook AM, Witwer AN, Hall KL, Thompson S and Ramadan $Y$. Atomoxetine for hyperactivity in autism spectrum disorders: placebo-controlled crossover pilot trial. J Am Acad Child Adolesc Psychiatry. 2006; 45:1196-205. | Article | PubMed

49. Arnold LE, Aman MG, Martin A, Collier-Crespin A, Vitiello B, Tierney E, Asarnow R, Bell-Bradshaw F, Freeman BJ, Gates-Ulanet P, Klin A, McCracken JT, McDougle CJ, McGough JJ, Posey DJ, Scahill L, Swiezy NB, Ritz $L$ and Volkmar F. Assessment in multisite randomized clinical trials of patients with autistic disorder: the Autism RUPP Network. Research Units on Pediatric Psychopharmacology. J Autism Dev Disord. 2000; 30:99-111. | PubMed

50. Lake J, Helgason C and Sarris J. Integrative Mental Health (IMH): paradigm, research, and clinical practice. Explore (NY). 2012; 8:50-7. | Article | PubMed

51. Sarris J et al. The International Network of Integrative Mental Health (INIMH). Advances in Integrative Medicine. 2014; 1:59-60. | Article

52. Akins RS, Angkustsiri $\mathrm{K}$ and Hansen RL. Complementary and alternative medicine in autism: an evidence-based approach to negotiating safe and efficacious interventions with families. Neurotherapeutics. 2010; 7:307-19. | Article | PubMed

53. Gutierrez E, J Silbert-Flagg and S Vohra. Natural health product use and management in pediatrics: An integrative review. European Journal of Integrative Medicine.2014; 6:226-233. | Article

54. Niggemann B and Gruber C. Side-effects of complementary and alternative medicine. Allergy. 2003; 58:707-16. | Article | PubMed

55. Hu Z et al. Herb-drug interactions: a literature review. Drugs. 2005; 65: 1239-1282. | PubMed

56. Robinson N, J Liu and M S Lee. Clinical guidelines: The way for best practice. European Journal of Integrative Medicine. 2014; 6:133-134.

57. Lorenc A, J Leach and N. Robinson. Clinical guidelines in the UK: Do they mention Complementary and alternative medicine (CAM) - Are CAM professional bodies aware? European Journal of Integrative Medicine. 2014; 6:164-175. | Article

58. Council A.G.N.H.M.R.C. Complementary Medicines. | Website

Citation:

Granich J, Hunt A, Ravine D, Wray J and Whitehouse AJO. High use of complementary and alternative medication among children with autism is not associated with the severity of core symptoms. J Autism. 2014; 1:4.

http://dx.doi.org/10.7243/2054-992X-1-4 